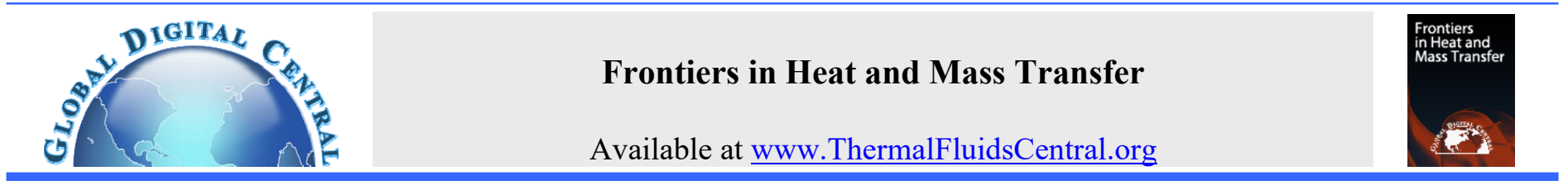

\title{
SIMULATION AND OPTIMIZATION OF MULTISTAGE COMPRESSED DMR NATURAL GAS LIQUEFACTION PROCESS
}

\author{
Rongge Xiao ${ }^{\mathrm{a},{ }^{*}}$, Yanwei Zhang ${ }^{\mathrm{a}}, \mathrm{Xu} \mathrm{Gao}^{\mathrm{b}}$, Hongping $\mathrm{Yu}^{\mathrm{c}}$, Wangying Wei ${ }^{\mathrm{a}}$ \\ a Shaanxi Key Laboratory of Advanced Stimulation Technology for Oil \& Gas Reservoirs, College of Petroleum Engineering, Xi'an Shiyou \\ University, Xian 710065, Shaanxi China \\ ${ }^{b}$ Shenzhen Branch of Sichuan East Gas Engineering Design and Research Institute, Shenzhen 518033, China \\ ${ }^{c}$ Production Technology Research Institute, The Second Oil Production Plant of Changqing Oilfield. Qingyang 745100, Gansu, China
}

\begin{abstract}
In order to improve DMR (double mixed refrigerant) liquefaction process and reduce operation cost of natural gas liquefaction plant, a four-stage DMR process optimization simulation calculation model was established through Aspen Hysys v8.4 and the purpose of the optimization model is achieved by using the segmented compression process in this paper. The minimum energy consumption and the highest exergy efficiency were used as the objective functions. By using the optimizer in HYSYS, the process parameters and ingredient proportion of the mixed refrigerant in the fourstage DMR process was optimized, and the best process parameters and ingredient proportion of the mixed refrigerant were obtained. According to process power consumption obtained by the optimization simulation, the ratio power consumption and exergy efficiency of the process were calculated. The liquefaction power consumption per unit quality of natural gas was $272.2 \mathrm{~kW} / \mathrm{t}$ and the liquefaction exergy efficiency was $46.85 \%$ in this paper. Comparing with the current DMR process power consumption in China, the energy consumption was significantly reduced.
\end{abstract}

Keywords: Natural gas liquefaction, Double mixed refrigerant (DMR), Exergy efficiency, Efficiency Improvement

\section{INTRODUCTION}

According to refrigeration method, the natural gas liquefaction process can be divided into cascading natural gas liquefaction process, mixed refrigerant natural gas liquefaction process and natural gas liquefaction process with expander. The mixed refrigerant liquefied natural gas process has been widely used in large-scale LNG liquefaction plants due to its advantages of low energy consumption (Fu et al., 2004; Remeljej et al., 2006; MAFI et al., 2009). At present, the mixed refrigerant processes mainly used in industry are: single mixed refrigerant process (SMR), propane pre-cooled mixed refrigerant process $\left(\mathrm{C}_{3} \mathrm{MR}\right), \mathrm{AP}-\mathrm{X}$ expansion process and double-cycle mixed refrigerant process (DMR), etc. (Shi et al., 2001; Yin et al., 2010; Zhao et al., 2010; Wang et al., 2015; Khan et al., 2015). There is no precooling stage in the SMR process. Since it is with large temperature difference in the heat exchanger, energy consumption of SMR process is very high. To improve the efficiency of processing natural gas, propane is used in $\mathrm{C}_{3} \mathrm{MR}$ process for pre-cooling while AP-X process adds a nitrogen expansion cycle to the super-cooled part of $\mathrm{C}_{3} \mathrm{MR}$ process. However, minimum temperature of the pre-cooling parts in these two processes is limited by boiling point of propane. In DMR process, mixed refrigerants are used instead of propane in $\mathrm{C}_{3} \mathrm{MR}$ process. By adjusting the proportion of the mixed refrigerant, the selection range of pre-cooling temperature of natural gas is expanded, and adaptability of the process to raw natural gas and external conditions is improved. If heat exchange temperature difference between natural gas and the mixed refrigerant in heat exchanger is relatively uniform during the liquefaction process, the exergy efficiency will be high (Nibbelke et al., 2002).

The use of the DMR process allows for significant degrees of freedom in the variation of the compositions of each low level (operating at low temperatures) and high level (operating at relatively high temperatures than low level) refrigeration cycles both in the makeup of the refrigerant and variation of the compositions. This feature of the DMR process allows for the re-matching of the liquefaction load without altering the equipment (Newton., 1988). Husnil and Lee examined the optimal control structure of the DMR process by drawing the steady-state optimality map containing information on the major state variables (Husnil, et al., 2014). Husnil believed that when the working refrigerant flow ratio was constant, the DMR process could obtain the optimal and stable operation. Due to its multi-phase refrigerant and the complexity of operation conditions, optimization design of DMR liquefaction process actually includes two aspects: circulating operation parameters optimization and mixture proportion optimization (Cao et al., 2005; Wang ., 2009; Meng et al., 2015; Yang et al., 2018). In natural gas liquefaction plants, the natural gas liquefaction unit occupies about $80 \%$ energy consumption of the entire plant, so how to use software to simulate and optimize the optimal proportion of mixed refrigerants and process operating parameters plays an important role in the liquefaction industry (Waldmann., 2008).

However, there are many constraints in optimization of the DMR liquefaction process. The optimization variables are often plenty, and the objective function is nonlinear, making it a complicated optimization problem. Hwang et al. used HYSYS to simulate and analyze the DMR process, and carried out numerical optimization by GA algorithm and SQP. After optimization, the compression power consumption was reduced by $34.5 \%$ compared with the patented (Roberts\&Agrawal2001) (Hwang et al., 2013). Khan et al. studied the development process of DMR process and conducted multiple singleobjective and multi-objective optimization studies on a DMR process

\footnotetext{
*Corresponding Author. E-mail: xiaorongge@163.com.
} 
(Khan et al., 2015). Qyyum et al. proposed a simple and highly efficient hybrid modified coordinate descent (HMCD) algorithm was proposed to cope with the optimization of the natural gas liquefaction processin in 2017(Qyyum et al., 2017). Then, investigated the uncertainty levels in the overall energy consumption and minimum internal temperature approach (MITA) inside LNG heat exchangers with variations in the operational variables of the DMR processes and a global sensitivity analysis is conducted to identify the influence of random inputs on the process performance parameters (Qyyum et al., 2019). An energy and cost-efficient dual-effect single mixed refrigerant (DSMR) process is proposed, and it employs a single loop refrigeration cycle to generate the dual cooling and subcooling effect, separately. The DMR process and the proposed DSMR process are simulated (with same design parameters) using well-known commercial simulator Aspen Hysys v10 (Qyyum et al., 2020).

In order to select economical and reasonable Boil-off gas (BOG) treatment technology for different types of liquified natural gas (LNG) stations, Xiao et al introduced the related technologies of BOG treatment (Xiao et al., 2020). Zhang calculated the power loss in pressure-driven mass transfer process using a multi-scale method (Zhang, 2019). Sun et al established a dynamic model of dual mixed refrigerant (DMR) liquefaction process and tested the dynamic responses of the DMR liquefaction process by selected variations of gas-phase and liquid-phase plugging ratios as disturbances.(Sun et al., 2017). For studying the performance of spiral wound heat exchangers (SWHEs) applied in the LNG-FPSO (LNG Floating Production Storage and Offloading unit) dual mixed refrigerant (DMR) liquefaction process, an experimental device and a numerical simulation model of DMR liquefaction process are established (Sun et al., 2019). The two DMR process configurations were optimized to maximize efficiency, and the risk of conceptual explosion was analyzed and compared in the conceptual design phase.(You et al., 2019).

The DMR process is divided into three parts: Natural gas liquefaction, pre-cooled mixed refrigerant cycle and mixed cryogen cycle. In order to reduce power consumption, the entire compression process was generally divided into multiple stages. After each stage of compression completed, the gas would be cooled before the next stage of compression. The significant reduction in power consumption was due to high dew point components of the pre-cooled refrigerant. After the first stage of compression and cooled by water cooler, part of the gas phase would be condensed into liquid, and the liquid phase would be pressurized by liquid pump, which would save more power consumption than that by gas compressor. After cooling by water cooler, gas flow rate of the uncondensed gas phase was reduced, and power consumption of the second stage compressor was also reduced. The precooling mixed refrigerant in the pre-cooling cycle adopted two-stage throttling, and the mixed cryogen in the cryogen cycle adopted twostage throttling, hence the whole process called "four-stage throttling DMR liquefaction” . Process of four-stage throttling DMR liquefaction is shown in Fig. 1.

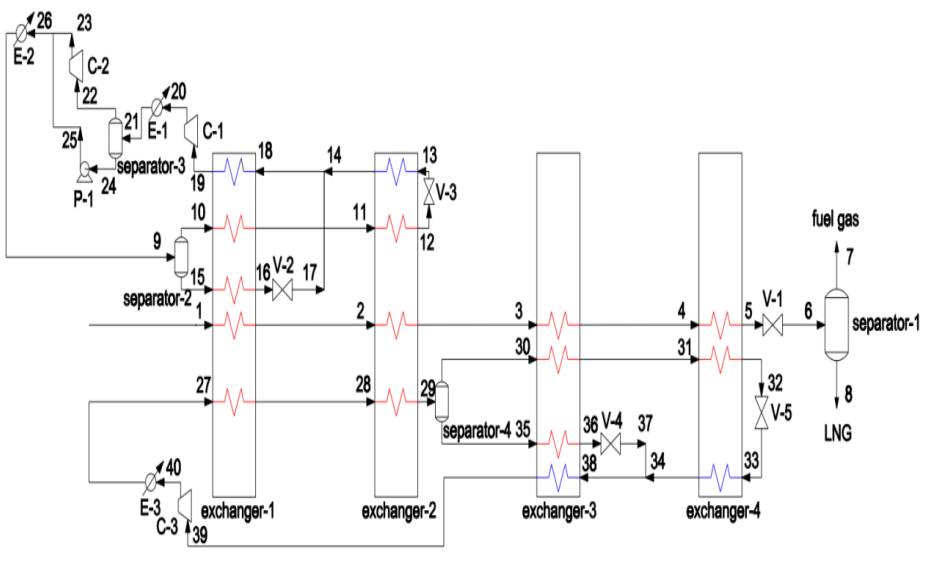

Fig. 1. Process of four-stage throttling DMR liquefaction
Natural gas liquefaction: After pre-treatment, the qualified natural gas would enter plate-fin heat exchanger 1 and 2 in turn and pre-cooled to $-60^{\circ} \mathrm{C}$, then plate-fin heat exchanger 3 for liquefaction and plate-fin heat exchanger 4 for cryogenic treatment. At the bottom of plate-fin heat exchanger 4 , liquefied natural gas would flow out at $-160^{\circ} \mathrm{C}$, then throttled and depressurized to $0.15 \mathrm{Mpa}$ through throttle valve 1 , and finally entered gas-liquid separator 1 . Then gas phase would serve as fuel gas in the plant area, and liquid phase would enter LNG storage tank as LNG products.

Pre-cool mixed refrigerant circulation: Composition of the precooled refrigerant was $\mathrm{C}_{2} \mathrm{H}_{4}, \mathrm{C}_{3} \mathrm{H}_{8}$ and i- $\mathrm{C}_{5} \mathrm{H}_{12}$. The high-pressure precooled refrigerant was separated by gas-liquid separator 2 , and the gas phase was cooled to $-60^{\circ} \mathrm{C}$ by plate-fin heat exchanger 1 and 2 . After throttling, depressurizing and cooling by throttle valve 3 , it returned to plate-fin heat exchanger 2 to provide cooling capacity; the liquid phase was cooled by the plate-fin heat exchanger 1. After being throttled, depressurized and cooled by throttle valve 2 , it was mixed with the precooled refrigerant flowing back from the plate-fin heat exchanger 2 and entered the plate-fin heat exchanger 1 to provide cooling capacity. After being compressed by compressor 1 , the pre-cooled refrigerant would enter interstage cooler 1. At this time, part of liquid phase would be condensed out, which need to be separated by separator 3 for gas-liquid separation. The gas phase would enter compressor 2 for pressurization, and the liquid phase would enter liquid pump for pressurization. Then mixed the gas and liquid phases, and cooled them by cooler 2 to make pre-cooling refrigerant return to the initial state. Hence the pre-cooling circulation was completed.

Mixed cryogen circulation: Composition of the cryogen is $\mathrm{CH}_{4}$, $\mathrm{C}_{2} \mathrm{H}_{4}, \mathrm{C}_{3} \mathrm{H}_{8}$ and $\mathrm{N}_{2}$. The high-pressure cryogen was pre-cooled to $-60^{\circ} \mathrm{C}$ by plate-fin heat exchanger 1 and 2 and was separated by gas-liquid separator 4 . The gas phase was cooled to $-160^{\circ} \mathrm{C}$ by plate-fin heat exchanger 3 and 4, After throttling, depressurizing and cooling by throttle valve 5 , it returned to plate-fin heat exchanger 4 to provide cooling capacity; The liquid phase was cooled by the plate-fin heat exchanger 3 . After being throttled, depressurized and cooled by throttle valve 4 , it was mixed with the pre-cooled refrigerant flowing back from the plate-fin heat exchanger 4 and entered the plate-fin heat exchanger 3 to provide cooling capacity. Then it was boosted by the compressor 3 and cooled to the initial state by the cooler 3 to complete the cryogenic circulation.

In this paper, the chemical process simulation software HYSYS was used to simulate and optimize the DMR process. By taking the minimum process volume as the objective function; pressure value of the high and low pressure of pre-cooled refrigerant, pressure value of the high and low pressure of cryogen, mole fraction of $\mathrm{C}_{2} \mathrm{H}_{4}, \mathrm{C}_{3} \mathrm{H}_{8}$ and i- $\mathrm{C}_{5} \mathrm{H}_{12}$ in pre-cooled refrigerant and mole fraction of $\mathrm{CH}_{4} 、 \mathrm{C}_{2} \mathrm{H}_{4}$ 、 $\mathrm{C}_{3} \mathrm{H}_{8}$ and $\mathrm{N}_{2}$ as decision variables, the process parameters and mixed refrigerant proportion in the process would be optimized by optimizer in HYSYS.

\section{OPTIMIZATION SIMULATION OF PROCESS}

Since HYSYS cannot optimize material composition directly, we divided the pre-cooled mixed refrigerant and mixed cryogen by Component Splitter module into single-component materials. Hence proportion of mixed refrigerant could be controlled by stream of single component material. Then they were mixed up by the Mixer module. Therefore in the HYSYS model diagram, parameters of node 8 and node 8-2 were the same, and parameters of node 19 and node 19-2 were the same. The HYSYS optimization calculation model of DMR liquefaction process is shown in Fig. 2.

Since raw natural gas and mixed refrigerant in DMR process were in a high-pressure state, the state equation method but not fugacity coefficient method was used because it was with smaller error in calculation of the gas-liquid balance of high-pressure natural gas and other light hydrocarbon mixtures. The equation was very accurate on phase equilibrium of light hydrocarbon mixtures such as natural gas, 
thus the PR equation was used to calculate the gas-liquid phase equilibrium.

Theoretically, the more components of the mixed refrigerant, the more uniform the heat exchange temperature difference of the cold and hot fluid in the heat exchanger. However, too many components will make the storage and distribution system very complicated. Therefore, it is particularly critical to select reasonable components of the mixed refrigerant (Meng et al., 2015; Fan et al., 2017; Q M et al., 2018).The refrigerant groups commonly used in natural gas liquefaction systems are $\mathrm{N}_{2}$ and $\mathrm{C}_{1} \sim \mathrm{C}_{5}$. The DMR liquefication process is divided into precooling cycle and cryogenic cycle. The pre-cooling cycle needs to cool natural gas from $30^{\circ} \mathrm{C}$ to $-60^{\circ} \mathrm{C}$. The pre-cooling mixed refrigerant group is divided into $\mathrm{C}_{2}-\mathrm{C}_{5}$, the cryogenic cycle needs to cool natural gas from $-60^{\circ} \mathrm{C}$ to $-160^{\circ} \mathrm{C}$, and the cryogenic mixed refrigerant group is divided into $\mathrm{C}_{1} \sim \mathrm{C}_{3}$ and $\mathrm{N}_{2}$.FIG. 3 shows the bubble point curves of the selected refrigerants $\mathrm{N}_{2}, \mathrm{CH}_{4}, \mathrm{C}_{2} \mathrm{H}_{4}, \mathrm{C}_{3} \mathrm{H}_{8}$ and $\mathrm{i}-\mathrm{C}_{5} \mathrm{H}_{12}$.

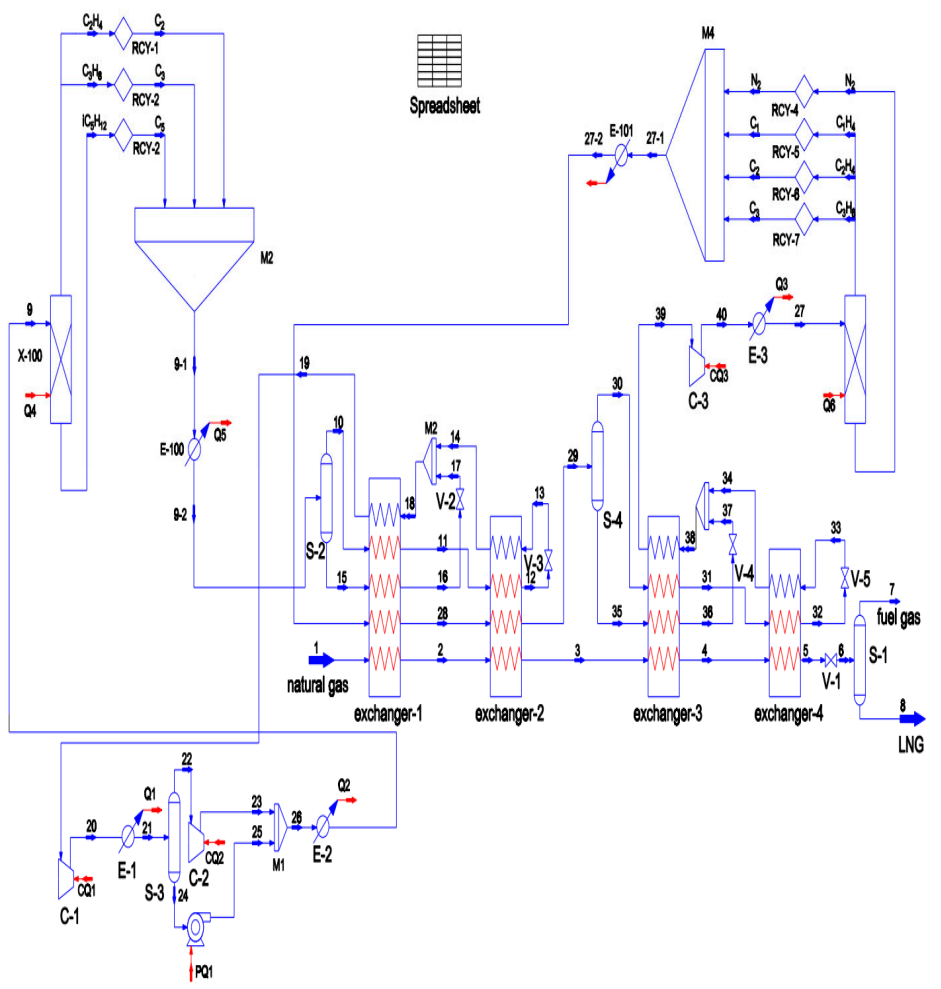

Fig. 2 Flow chart of fitting parameters of optimization algorithm combined with L-M and global optimization method

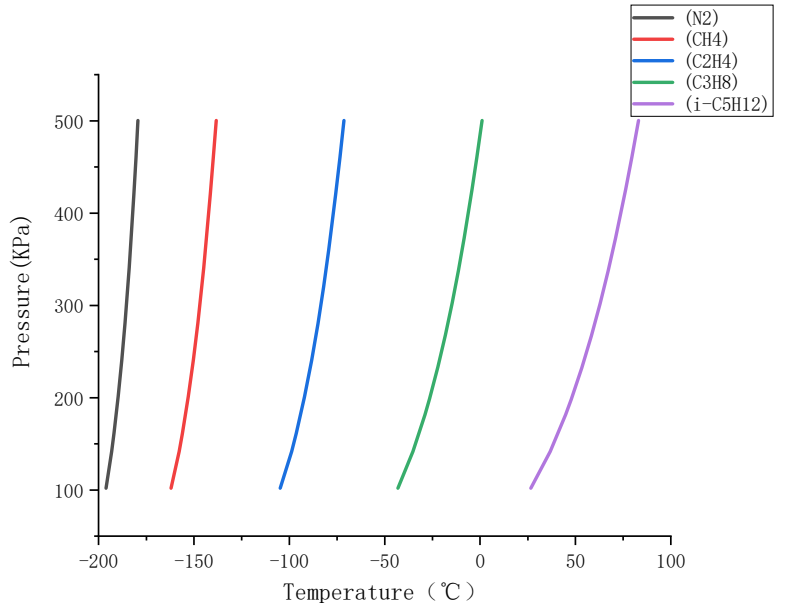

Fig. 3 The bubble point curves of the selected refrigerants $\mathrm{N}_{2}, \mathrm{CH}_{4}$, $\mathrm{C}_{2} \mathrm{H}_{4}, \mathrm{C}_{3} \mathrm{H}_{8}$ and $\mathrm{i}-\mathrm{C}_{5} \mathrm{H}_{12}$
In order to make the simulation results more suitable for the actual operating conditions, it was necessary to set some reasonable assumptions before simulating and optimizing the DMR liquefaction process. The assumptions of the DMR process simulation in Table 1

Raw natural gas was supplied by the gas transmission line, and a pretreatment unit was required before the natural gas liquefaction unit. The pretreatment unit would remove solid impurities, acid gases $\left(\mathrm{CO}_{2}\right.$, $\mathrm{H}_{2} \mathrm{~S}$ ), water, mixed hydrocarbons, benzene, mercury and other harmful substances contained in raw natural gas, so that the natural gas could met the gas supply standard of the liquefaction unit being transmitted by gas pipelines. The natural gas environmental parameters and the raw gas composition are listed in Table 2

Initial parameters of HYSYS simulation for the four-stage throttling DMR liquefaction process were as follows: (1) Storage pressure of liquefied natural gas was $0.15 \mathrm{MPa}$; (2) The ambient temperature was $20^{\circ} \mathrm{C}$; (3) Temperature of the hot stream entering platefin heat exchanger 1 was $30^{\circ} \mathrm{C}$; (4) Temperature of the hot stream out of plate-fin heat exchanger 1 was $-20^{\circ} \mathrm{C}$; (5) Temperature of the hot stream out of plate-fin heat exchanger 2 was $-60^{\circ} \mathrm{C}$; (6)Temperature of the hot stream out of plate-fin heat exchanger 3 was $-120^{\circ} \mathrm{C}$; (7) Temperature of the hot stream out of plate-fin heat exchanger 4 was $-160^{\circ} \mathrm{C}$.

\section{RESULTS AND DISCUSSION}

\subsection{Results of simulation}

Through optimization and simulation of the process, we had state parameters of each node of the process (see Tab. 3.), components of pre-cooled mixed refrigerant, mixed cryogen, LNG and fuel gas (see Tab. 4.), as well as the liquefaction rate of natural gas and process parameters (see Tab. 5). Molar flow rate of natural gas was $1000 \mathrm{kmol} / \mathrm{h}$, molar flow rate of LNG was $982.14 \mathrm{kmol} / \mathrm{h}$, and liquefaction rate of natural gas was $98.214 \%$.

\subsection{Heat exchange temperature difference of four-stage throttling DMR process heat exchanger}

To make heat exchange between natural gas and refrigerant work, there must be a certain heat exchange temperature difference. However, heat exchange temperature difference will cause exergy loss. If local heat exchange temperature difference in the heat exchanger is too small, heat exchange area required in the exchanger will increase sharply. Generally in engineering, the minimum heat exchange temperature difference in heat exchanger is $3^{\circ} \mathrm{C}$.

In order to reduce the exergy loss and making heat exchange temperature difference in heat exchanger relatively uniform, in this paper, we optimized the mixed refrigerant proportion and process parameters; hence the average heat exchange temperature difference in heat exchanger was reduced while ensuring the minimum temperature difference in the heat exchanger unchanged. Fig. 4(a), (c), (e), and (g) are the optimized cooling and heating composite curves of heat exchangers 1, 2, 3, and 4; Fig. 4(b), (d), (f), and (h) are heat exchange temperature difference of cold and hot streams in heat exchangers 1, 2, 3 , and 4 respectively.

As can be seen from Figure 4, the heat exchange temperature difference of heat exchanger 1 increases roughly with the increase of temperature, reaching the minimum value of $3.00^{\circ} \mathrm{C}$ at $-20^{\circ} \mathrm{C}$ and the maximum value of $10.19^{\circ} \mathrm{C}$ at $29.49^{\circ} \mathrm{C}$. The heat exchange temperature difference of heat exchanger 2 first increases and then decreases with the increase of temperature, then slightly increases and then decreases, reaching the minimum value of $3.56^{\circ} \mathrm{C}$ at $-60^{\circ} \mathrm{C}$ and the maximum value of $5.78^{\circ} \mathrm{C}$ at $-51.13^{\circ} \mathrm{C}$. The heat exchange temperature difference of heat exchanger 3 first decreases, then increases and then decreases with the increase of temperature, reaching the minimum value of $3.04^{\circ} \mathrm{C}$ at $-120^{\circ} \mathrm{C}$ and the maximum value of $8.09^{\circ} \mathrm{C}$ at $-135.75^{\circ} \mathrm{C}$. The heat exchange temperature difference of heat exchanger 4 first increases, then decreases and then increases with the increase of temperature, 
reaching the minimum value of $3.05^{\circ} \mathrm{C}$ at $-69.71^{\circ} \mathrm{C}$ and the maximum value of $11.21^{\circ} \mathrm{C}$ at $-84.01^{\circ} \mathrm{C}$.

It can be seen from Fig. 3 that heat exchange temperature of hot and cold streams in the four heat exchangers was small and relatively

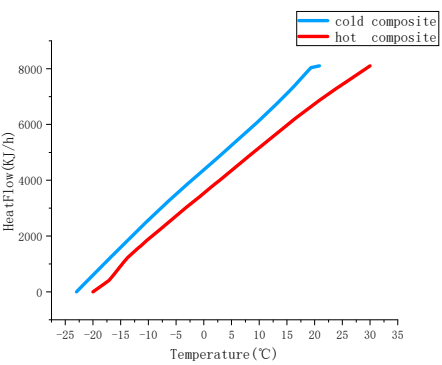

(a) optimized cooling and heating composite curves of heat exchangers 1

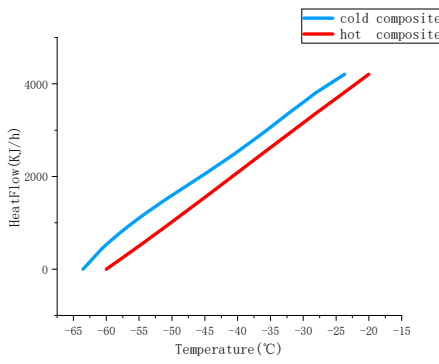

(c) optimized cooling and heating composite curves of heat exchangers 2

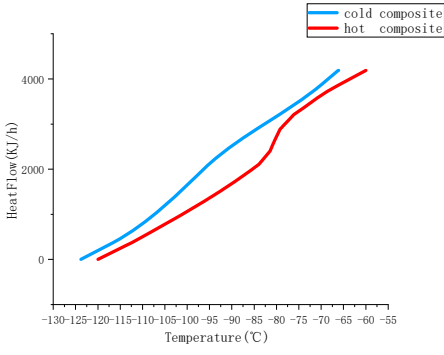

(e) optimized cooling and heating composite curves of heat exchangers 3

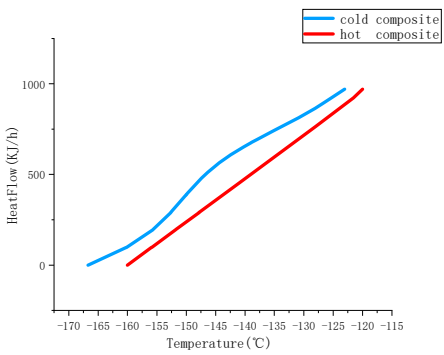

(g) optimized cooling and heating composite curves of heat exchangers 4

Fig. 4. The optimized cooling and heating composite curves and heat exchange temperature difference of cold and hot streams in heat exchangers

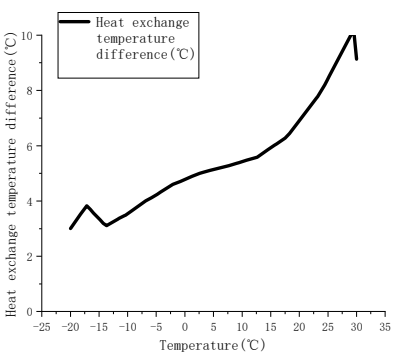

(b) heat exchange temperature difference of cold and hot streams in heat exchangers 1

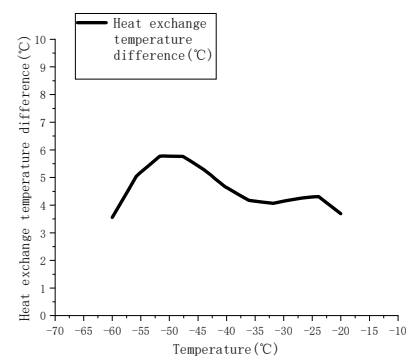

(d) heat exchange temperature difference of cold and hot streams in heat exchangers 2

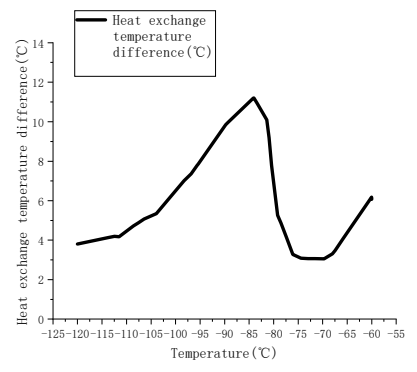

(f) heat exchange temperature difference of cold and hot streams in heat exchangers 3

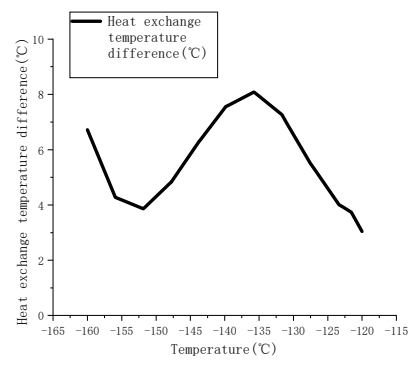

(h) heat exchange temperature difference of cold and hot streams in heat exchangers 4 uniform, which meant exergy loss in the liquefaction process is reduced, thereby power consumption of the four-stage throttling DMR process was reduced too.

\subsection{Process energy consumption and efficiency}

(1) Calculation of ratio power consumption

$J=\frac{Q}{q_{L N G}}=\frac{Q_{C 1}+Q_{C 2}+Q_{C 3}+Q_{P 1}}{q_{L N G}}$

(2) Calculation of theoretical liquefaction work of natural gas

$\mathrm{W}=\mathrm{h}_{2}-\mathrm{h}_{1}-\mathrm{T}_{0}\left(\mathrm{~s}_{2}-\mathrm{s}_{1}\right)$

(3) Calculation of liquefaction exergy efficiency

$\eta=\frac{\mathrm{W}}{\mathrm{J}}$

After optimization, consumption of compressor $1 \mathrm{Q}_{\mathrm{C} 1}=1580.5 \mathrm{kw}$, consumption of compressor $2 \mathrm{Q}_{\mathrm{C} 2}=735 \mathrm{kw}$, consumption of compressor $3 \mathrm{QC}_{3}=2185 \mathrm{kw}$, consumption of centrifugal pump $1 \mathrm{Qp}_{1}=9.1 \mathrm{kw}$, total consumption $\mathrm{Q}=4509.6 \mathrm{kw}$, ratio power consumption $\mathrm{J}=272.2 \mathrm{~kW} / \mathrm{t}$, and liquefaction exergy efficiency $\eta=46.85 \%$.

Among the existing LNG plants in China, the liquefaction units of Shaanxi Ansai and Shandong Tai' an LNG plant adopt the DMR liquefaction process of China Global Engineering Corporation.The power consumption comparison between this paper and domestic current DMR process is shown in Table 6.

It can be seen from Table 6 that compared with the DMR liquefaction processes in Shaanxi Ansai and Shandong Tai 'an the ratio power consumption under the optimal parameters obtained through optimization simulation in this paper is reduced by $29.11 \%$ and $14.07 \%$ respectively.Liquefied exergy efficiency increased by $33.86 \%$ and $23.94 \%$ respectively.

\section{CONCLUSIONS}

In this paper, the HYSYS software was used to optimize process parameters of DMR liquefaction process and proportion of mixed refrigerant. The conclusions are as follows:

(1) Since HYSYS cannot optimize material composition directly, we divided the pre-cooled mixed refrigerant and mixed cryogen by Component Splitter module into single-component materials. Hence proportion of mixed refrigerant could be controlled by stream of single component material and an optimized simulation calculation model could be established in HYSYS. Taking the minimum energy consumption of the process as objective function, the optimal process parameters and proportion of mixed refrigerant were obtained. Ratio power consumption and exergy efficiency of the natural gas liquefaction process were calculated according to power consumption of the process.

(2) For DMR process under the same natural gas intake condition, increasing throttling stages of mixed refrigerant circulation, the average heat exchange temperature difference in plate-fin heat exchanger would be reduced, so the exergy loss during heat exchange would be reduced also. In this case efficiency of the process would be improved and the total energy consumption and ratio power consumption of the process would be reduced.

(3) Through optimization simulation of the four-stage throttling DMR process, ratio power consumption of the liquefaction process was $272.2 \mathrm{kw} / \mathrm{t}$, and the liquefaction exergy efficiency was $46.85 \%$. Compared with the DMR liquefaction processes in Shaanxi Ansai and Shandong Tai 'an the ratio power consumption in this paper is reduced by $29.11 \%$ and $14.07 \%$ respectively.Liquefied exergy efficiency increased by $33.86 \%$ and $23.94 \%$ respectively 
Table. 1. Assumptions of the DMR process simulation

\begin{tabular}{|c|c|}
\hline Parameter & Value \\
\hline Adiabatic compressor efficiency & $75 \%$ \\
\hline Minimum temperature approach of cold box $\left({ }^{\circ} \mathrm{C}\right)$ & 3 \\
\hline Heat leakage of cold box & $0 \%$ \\
\hline Pressure of natural gas entering cold box $(\mathrm{MPa})$ & 5 \\
\hline Temperature of hot stream at cold box inlet $\left({ }^{\circ} \mathrm{C}\right)$ & 30 \\
\hline Comperature of natural gas at cold box outlet $\left({ }^{\circ} \mathrm{C}\right)$ & -160 \\
\hline Compressor inlet pressure $(\mathrm{MPa})$ & $<150$ \\
\hline Compressor inlet vapour phase fraction & $>0.15$ \\
\hline
\end{tabular}

Table. 2. Natural gas environmental parameters and the raw gas composition

\begin{tabular}{|c|c|}
\hline Parameter & Value \\
\hline Natural gas processing capacity $(\mathrm{kmol} / \mathrm{h})$ & 1000 \\
\hline Temperature of hot stream at cold box inlet $\left({ }^{\circ} \mathrm{C}\right)$ & 30 \\
\hline Pressure of natural gas entering cold box $(\mathrm{MPa})$ & 5 \\
\hline Composition of natural gas $(\% \mathrm{~mol})$ & \\
\hline $\mathrm{N}_{2}$ & 1.52 \\
\hline $\mathrm{CH}_{4}$ & 95.42 \\
\hline $\mathrm{C}_{2} \mathrm{H}_{6}$ & 2.04 \\
\hline $\mathrm{C}_{3} \mathrm{H}_{8}$ & 0.51 \\
\hline $\mathrm{i}-\mathrm{C}_{4} \mathrm{H}_{10}$ & \\
\hline $\mathrm{n}-\mathrm{C}_{4} \mathrm{H}_{10}$ & \\
\hline
\end{tabular}

Table. 3. Each node state parameter of process

\begin{tabular}{|c|c|c|c|c|c|c|}
\hline Node number & $\begin{array}{c}\mathrm{T} \\
\left({ }^{\circ} \mathrm{C}\right)\end{array}$ & $\begin{array}{c}\mathrm{P} \\
(\mathrm{kPa})\end{array}$ & $\begin{array}{c}\text { Mole-Flow } \\
(\mathrm{kmol} / \mathrm{h})\end{array}$ & $\begin{array}{c}\text { Rate of gasification } \\
(\%)\end{array}$ & $\begin{array}{c}\text { Enthalpy } \\
\left(\mathrm{kJ} / \mathrm{kmol} \times 10^{5}\right)\end{array}$ & $\begin{array}{c}\text { entropy } \\
{\left[\mathrm{kJ} /\left(\mathrm{kmol} \cdot{ }^{\circ} \mathrm{C}\right)\right]}\end{array}$ \\
\hline 1 & 30.0 & 5000.0 & 1000.00 & 100 & -0.74656 & 151.20 \\
\hline 2 & -20.0 & 5000.0 & 1000.00 & 100 & -0.76868 & 143.21 \\
\hline 3 & -60.0 & 5000.0 & 1000.00 & 99.77 & -0.79095 & 133.58 \\
\hline 4 & -120.0 & 5000.0 & 1000.00 & 0 & -0.86487 & 94.28 \\
\hline 5 & -160.0 & 5000.0 & 1000.00 & 0 & -0.88879 & 76.19 \\
\hline 6 & -160.4 & 150.0 & 1000.00 & 1.79 & -0.88879 & 77.80 \\
\hline 7 & -160.4 & 150.0 & 17.86 & 100 & -0.60035 & 143.25 \\
\hline 8 & -160.4 & 1500 & 982.14 & 0 & -0.89404 & 76.61 \\
\hline 9 & 30.0 & 1363.9 & 2047.82 & 48.41 & -0.72495 & 117.58 \\
\hline 10 & 30.0 & 1363.9 & 991.27 & 100 & -0.27150 & 150.89 \\
\hline 11 & -20.0 & 1363.9 & 991.27 & 0 & -0.43582 & 91.68 \\
\hline 12 & -60.0 & 1363.9 & 991.27 & 0 & -047168 & 76.28 \\
\hline 13 & -63.5 & 336.7 & 991.27 & 2.72 & -0.47168 & 76.61 \\
\hline 14 & -23.8 & 336.7 & 991.27 & 87.58 & -0.31823 & 143.70 \\
\hline 15 & 30.0 & 1363.9 & 1056.55 & 0 & -1.15038 & 86.33 \\
\hline 16 & -20.0 & 1363.9 & 1056.55 & 0 & -1.21137 & 64.40 \\
\hline 17 & -25.6 & 336.7 & 1056.55 & 5.06 & -1.21137 & 64.76 \\
\hline 18 & -23.0 & 336.7 & 2047.82 & 44.22 & -0.77904 & 102.99 \\
\hline 19 & 23.4 & 336.7 & 2047.82 & 100 & -0.63518 & 155.87 \\
\hline 20 & 64.5 & 800.0 & 2047.82 & 100 & -0.60739 & 157.95 \\
\hline 21 & 30.0 & 800.0 & 2047.82 & 79.37 & -0.67504 & 136.53 \\
\hline 22 & 30.0 & 800.0 & 1625.27 & 100 & -0.48453 & 153.21 \\
\hline 23 & 58.7 & 1363.9 & 1625.27 & 100 & -0.46825 & 154.44 \\
\hline 24 & 30.0 & 800.0 & 422.55 & 0 & -1.40784 & 72.38 \\
\hline 25 & 30.4 & 1363.9 & 422.55 & 0 & -1.40707 & 72.44 \\
\hline 26 & 49.6 & 1363.9 & 2047.82 & 78.89 & -0.66196 & 137.62 \\
\hline 27 & 30.0 & 1948.7 & 1216.62 & 100 & -0.14109 & 159.21 \\
\hline
\end{tabular}




\begin{tabular}{|c|c|c|c|c|c|c|}
\hline 28 & -20.0 & 1948.7 & 1216.62 & 90.59 & -0.17819 & 145.53 \\
\hline 29 & -60.0 & 1948.7 & 1216.62 & 34.88 & -0.25570 & 112.37 \\
\hline 30 & -60.0 & 1948.7 & 424.40 & 100 & -0.34651 & 145.97 \\
\hline 31 & -120.0 & 1948.7 & 424.40 & 0 & -0.44707 & 91.05 \\
\hline 32 & -160.0 & 1948.7 & 424.40 & 0 & -0.47181 & 72.33 \\
\hline 33 & -166.0 & 195.5 & 424.40 & 7.42 & -0.47181 & 73.00 \\
\hline 34 & -123.1 & 195.5 & 424.40 & 77.84 & -0.39069 & 136.51 \\
\hline 35 & -60.0 & 1948.7 & 792.22 & 0 & -0.20705 & 94.37 \\
\hline 36 & -120.0 & 1948.7 & 792.22 & 0 & -0.25099 & 70.20 \\
\hline 37 & -125.4 & 195.5 & 792.22 & 6.16 & -0.25099 & 70.97 \\
\hline 38 & -123.9 & 195.5 & 1216.62 & 31.21 & -0.29972 & 93.96 \\
\hline 39 & -65.6 & 195.5 & 1216.62 & 100 & -0.17528 & 163.73 \\
\hline 40 & 88.6 & 1948.7 & 1216.62 & 100 & -0.11063 & 168.40 \\
\hline
\end{tabular}

Table. 4. Mole fraction of fuel gas

\begin{tabular}{|c|c|c|c|c|}
\hline Component & $\begin{array}{c}\text { Pre-cooled mixed } \\
\text { refrigerant } \\
(\%)\end{array}$ & $\begin{array}{c}\text { Cryogenic mixed } \\
\text { refrigerant } \\
(\%)\end{array}$ & LNG & Fuel gas \\
\hline $\mathrm{N}_{2}$ & - & 3.94 & $1.52 \%$ & $28.02 \%$ \\
\hline $\mathrm{CH}_{4}$ & - & 32.5 & $95.42 \%$ & $71.98 \%$ \\
\hline $\mathrm{C}_{2} \mathrm{H}_{4}$ & 32.22 & 49.16 & - & - \\
\hline $\mathrm{C}_{2} \mathrm{H}_{6}$ & - & - & $2.04 \%$ & - \\
\hline $\mathrm{C}_{3} \mathrm{H}_{8}$ & 49.22 & 14.4 & $0.51 \%$ & - \\
\hline $\mathrm{i}-\mathrm{C}_{4} \mathrm{H}_{10}$ & - & - & $0.35 \%$ & - \\
\hline $\mathrm{n}-\mathrm{C}_{4} \mathrm{H}_{10}$ & - & - & $0.16 \%$ & - \\
\hline $\mathrm{i}-\mathrm{C}_{5} \mathrm{H}_{12}$ & 18.56 & - & - & - \\
\hline
\end{tabular}

Table. 5. Optimal process parameters

\begin{tabular}{|c|c|}
\hline Parameter & Optimized simulation results \\
\hline Pre-cooled cycle high pressure/ $\mathrm{MPa}$ & 1.3639 \\
\hline Pre-cooled cycle low pressure/ $\mathrm{MPa}$ & 0.3367 \\
\hline Cryogenic cycle high pressure/ $\mathrm{MPa}$ & 1.9487 \\
\hline Cryogenic cycle low pressure/ $\mathrm{MPa}$ & 0.1955 \\
\hline Natural gas flow/ $\left(\mathrm{kmol} \cdot \mathrm{h}^{-1}\right)$ & 982.14 \\
\hline Pre-cooled mixed refrigerant flow/ $\left(\mathrm{kmol} \cdot \mathrm{h}^{-1}\right)$ & 2047.8 \\
\hline Cryogenic mixed refrigerant flow/ $\left(\mathrm{kmol} \cdot \mathrm{h}^{-1}\right)$ & 1216.6 \\
\hline
\end{tabular}

Table. 6. Power Consumption comparison

\begin{tabular}{|c|c|c|c|c|c|c|}
\hline \multirow{2}{*}{ Project } & \multirow{2}{*}{$\begin{array}{l}\text { Pressure } \\
(\mathrm{MPa})\end{array}$} & \multicolumn{3}{|c|}{$\begin{array}{c}\text { Mole fraction } \\
(\%)\end{array}$} & \multirow{2}{*}{$\begin{array}{l}\text { Ratio power consumption } \\
\qquad(\mathrm{kw} / \mathrm{t})\end{array}$} & \multirow{2}{*}{$\begin{array}{c}\text { Liquefaction exergy efficiency } \\
(\%)\end{array}$} \\
\hline & & $\mathrm{N}_{2}$ & $\mathrm{CH}_{4}$ & $\mathrm{C}_{2}-\mathrm{C}_{4}$ & & \\
\hline This paper & 5 & 1.52 & 95.42 & 3.06 & 272.2 & 46.85 \\
\hline Shaanxi Ansai & 4.1 & 0.3 & 99.1 & 0.6 & 384.0 & 35.00 \\
\hline Shandong Tai'an & 5.9 & 0.8 & 95.8 & 3.4 & 316.8 & 37.80 \\
\hline
\end{tabular}

\section{ACKNOWLEDGE}

This work was supported by the Xi 'an Science and Technology Project (2019217914GXRC015CG016-GXYD15.2) and Xi'an Petroleum University postgraduate innovation and practice ability training program, so grateful here.

\section{NOMENCLATURE}

$J \quad$ Ratio power consumption, $\mathrm{kW} / \mathrm{t}$

$Q \quad$ Total system power consumption, $\mathrm{kW} / \mathrm{h}$
$Q_{C 1} 、 Q_{C 2}$ Power consumption of pre-cooled mixed refrigerant cycle compressors 1 and $2, \mathrm{~kW} / \mathrm{h}$

$Q_{3} \quad$ Power consumption of cryogenic mixed refrigerant cycle compressor $3, \mathrm{~kW} / \mathrm{h}$

$Q_{P 1} \quad$ Power consumption of pre-cooled mixed refrigerant cycle pump $1, \mathrm{~kW} / \mathrm{h}$

$q_{L N G}$ LNG flow, $\mathrm{t} / \mathrm{h}$

$W \quad$ Theoretical liquefaction work of natural gas, $\mathrm{kW} / \mathrm{t}$

$h_{1} \quad$ Enthalpy of natural gas entering the first plate-fin heat exchanger, $\mathrm{kW} / \mathrm{t}$ 
$h_{2} \quad$ Enthalpy of natural gas flowing out of the last plate-fin heat exchanger, $\mathrm{kW} / \mathrm{t}$

$T_{0} \quad$ Environment temperature, $\mathrm{K}$

$s_{1} \quad$ Entropy of natural gas entering the first plate-fin heat exchange, $\mathrm{kW} /(\mathrm{t} \cdot \mathrm{K})$

$s_{2} \quad$ Entropy of natural gas flowing out of the last plate-fin heat exchanger, $\mathrm{kW} /(\mathrm{t} \cdot \mathrm{K})$

$\eta \quad$ Liquefaction exergy efficiency.

\section{REFERENCES}

Fu, DM., Sun, J., He ,ZQ., Cen, GY., and Yu, XC., 2004. "Research Progress of Natural Gas Pretreatment and Liquefaction Technology." Chemical Engineering of Oil and Gas, 033(004): 240-244.

https://doi.org/10.3969/j.issn.1007-3426.2004.04.007

Remeljej, C.W., and Hoadley, A.F.A., 2006. "An Exergy Analysis Small-Scale Liquefied Natural Gas (LNG) Liquefaction Process." Energy, 31(12): 2005-2019.

https://doi.org/10.1016/j.energy.2005.09.005

MAFI, M., AMIDPOUR, M., and NAEYNIAN, S.M.M., 2009. "Develop-Ment in Mixed Refrigerant Cycles Used in Olefin Plants." Proceedings of Annual Gas Processing Symposium, 1: 154-161. https://doi.org/10.1016/B978-0-444-53292-3.50021-3

Shi, YM., Yang, MZ., Lu, XS., and Wang, RS., 2001. "Optimization Analysis of Circulating Liquefied Natural Gas (LNG) with Propane Pre-Cooled Mixed Refrigerant." Natural Gas Industry, 21(2): 107-110. https://doi.org/10.3321/j.issn:1000-0976.2001.02.027

Wang, YC., Cheng, XJ., Gao, J., Wang, SQ., and CAO, LJ., 2015. "Study on the Mixed Refrigerant of the Two-Mixed Refrigerant Liquefied Natural Gas (LNG) Process." Chemical Engineering of Oil and Gas, 000(003): 50-53.

https://doi.org/10.3969/j.issn.1007-3426.2015.03.011

Yin, QS., Li, HY., Cui, JS., Ji, ZM., and Jia, LX., 2010. "Study on Adaptability and Regulating Ability of Liquefaction Cycle of Single Stage Mixed Refrigerant." Cryogenics, (01): 4-7.

https://doi.org/10.3969/j.issn.1000-6516.2010.01.001

Zhao, M., and Li, YZ., 2010. "Analysis for Selecting Mixed Refrigerant Composition Based on Raw Natural Gas in Propane Pre-Cooled Mixed Refrigerant Liquefaction Process." Journal of Xi'an Jiaotong University, 044(002): 108-112.

doi:CNKI:SUN:XAJT.0.2010-02-021

Khan, M.S., Karimi, I.A., and Lee, M ., 2015. "Evolution and Optimization of the Dual Mixed Refrigerant Process of Natural Gas Liquefaction." Applied Thermal Engineering, 96: 320-329.

https://doi.org/10.1016/j.applthermaleng.2015.11.092

Nibbelke, R., Kauffman, S., and Pek, B., 2002. "Double Mixed Refrigerant LNG Process Provides Viable Alternative for Tropical Conditions." Oil and Gas Journal, 100(27):64-66.

Newton, C.L., 1988. "Dual Mixed Refrigerant Natural Gas Liquefaction with Staged Compression.” European Patent No. 0141378, US Patents.

Husnil, Y.A. and M, Lee., 2014. "Synthesis of an Optimizing Control Structure for Dual Mixed Refrigerant Process." Journal of Chemical Engineering of Japan, 47(8): p. 678-686.

https://doi.org/10.1252/jcej.14we098
Wang, BQ., 2009. "Comparative Analysis of Natural Gas Liquefaction Technology.” Natural Gas Industry, 029(001): 111-113.

https://doi.org/10.3787/j.issn.1000-0976.2009.01.032

Meng, YM., Wang. DJ., and Chen, B., 2015. "Study on Formula Optimization of Mixed Refrigerant for Natural Gas Liquefaction." Chemical Engineering of Oil and Gas, (03): 81-85. https://doi.org/10.3969/j.issn.1007-3426.2015.03.014

Yang, XL., Fan, DD., Yuan, RN., Zhang, X., Ju, JP., and Li, WH., 2018. "Optimization of Design Parameters and Ratio of Mixed Coolant in MRC Process.” Chemical Engineering, 046(001): 1-6,20. https://doi.org/10.3969/j.issn.1005-9954.2018.01.001

Cao, WS., Lu, XS., Shi, YM., and Wang, RS., 2005. "Small Scale LNG Liquefaction Process.” Natural Gas Industry, 025(005): 109-111. https://doi.org/10.3321/j.issn:1000-0976.2005.05.035

I. B. Waldmann., 2008. "Evaluation of Process Systems for Floating LNG Production Units.” Tekna Conference.

Ji-Hyun Hwang., Myung-Il Roh., and Kyu-Yeul Lee., 2013. "Determination of the Optimal Operating Conditions of the Dual Mixed Refrigerant Cycle for the LNG FPSO Topside Liquefaction Process." Computers \& Chemical Engineering, 49:25-36.

https://doi.org/10.1016/j.compchemeng.2012.09.008

Wang, M., R. Khalilpour., and A. Abbas., 2014. "Thermodynamic and Economic Optimization of LNG Mixed Refrigerant Processes.” Energy Conversion and Management, 88: p. 947-961.

https://doi.org/10.1016/j.enconman.2014.09.007

Khan, M.S., Lee, S., Rangaiah, G.P., and Lee, M., 2013. "Knowledge Based Decision Making Method for the Selection of Mixed Refrigerant Systems for Energy Efficient LNG Processes." Applied Energy, 111: p. 1018-1031.

https://doi.org/10.1016/j.apenergy.2013.06.010

Khan, M.S., Husnil, YA., Yong, SK., and Lee, M., 2011 "Automated Optimization of Process Plant Using Particle Swarm Optimization." Advanced Control of Industrial Processes (ADCONIP), International Symposium on. 2011. IEEE.

https://doi.org/10.4218/etrij.13.0213.0197

Yin, QS., li, HY., Ji, ZM., Cui, JS., Du, HP., Fan, QH., and Jia LX., 2009 "The Effect of Series of Mixed Refrigerant Cycle on Refrigeration Performance." Journal of Chemical Industry and Engineering, (11): 1923.

https://doi.org/10.1007/978-0-387-74660-9 12

Nogal, F.D., Kim, J.K., Perry, S., and Smith, R., 2008. "Optimal Design of Mixed Refrigerant Cycles." Industrial \& Engineering Chemistry Research, 47(22): 8724-8740.

https://doi.org/10.1021/ie800515u

Trotter, I.M., Maciel, Gomes, M.F., Braga, M.J., and Brochmann, B., 2016. "Optimal LNG (Liquefied Natural Gas) Regasification

Scheduling for Import Terminals with Storage.” Energy,

105(jun.15):80-88.

https://doi.org/10.1016/j.energy.2015.09.004

Liu, J., Bai, GL., and Ji, ML., 2016. "Method for Advancement Evaluation of Natural Gas Liquefaction Process." Chemical Engineering, 44(11): 69-73.

doi:10.3969/j.issn.1005-9954.2016.11.013 
Qyyum, M.A., Long, N.V.D., Minh, L.Q., and Lee, M., 2017. "Design Optimization of Single Mixed Refrigerant LNG Process Using a Hybrid Modified Coordinate Descent Algorithm." Cryogenics, 89:131-140. $\underline{\text { https://doi.org/10.1016/j.cryogenics.2017.12.005 }}$

Qyyum, M.A., Duong, P.L.T., Minh, L.Q., Lee, S., and Lee, M., 2019. "Dual Mixed Refrigerant LNG Process: Uncertainty Quantification and Dimensional Reduction Sensitivity Analysis." Applied Energy, 250:1446-1456.

https://doi.org/10.1016/j.apenergy.2019.05.004

Qyyum, M.A., He, T., Qadeer, K., Mao, N., and Lee, M., 2020. "DualEffect Single-Mixed Refrigeration Cycle: An Innovative Alternative Process for Energy-Efficient and Cost-Effective Natural Gas Liquefaction.” Applied Energy, 268:115022.

https://doi.org/10.1016/j.apenergy.2020.115022

Xiao, R., Dai, Z., Sun, L., Zhu, Y., and Lin, H., 2020. "Comparison of BOG Treatment Technology in LNG Station Without LNG Output." Frontiers in Heat and Mass Transfer, 14. $\underline{\text { https://doi.org/10.5098/hmt.14.2 }}$

Zhang, Y., 2019. "Power Loss in Multiscale Mass Transfer." Frontiers in Heat and Mass Transfer, 13:22.

https://doi.org/10.5098/hmt.13.22
Moein, P., Sarmad, M., Ebrahimi, H., Marziyeh, Z., Pakseresht, S., and Vakili, S.Z., 2015. "APCI- LNG Single Mixed Refrigerant Process for Natural Gas Liquefaction Cycle: Analysis and Optimization." Journal of Natural Gas Science and Engineering, 26:470 - 479 https://doi.org/10.1016/j.jngse.2015.06.040

Sun, C., Li, Y., Han, H., Zhu, J., and Wang, Y., 2017. "Sensibility Analysis of Pre-cooling Cold Box Pipeline Blockage in DMR Liquefaction Process.” Energy Procedia, 142:3276-3281.

https://doi.org/10.1016/j.egypro.2017.12.457

Sun, C., Li, Y., Han, H., Wang, S., and Liu, L., 2019. "Experimental and Numerical Simulation Study on the Offshore Adaptability of Spiral Wound Heat Exchanger in LNG-FPSO DMR Natural Gas Liquefaction Process.” Energy, 189(PT.1):116178.1-116178.30. https://doi.org/10.1016/j.energy.2019.116178

You, W., Park, J., Jung, S., and Lim, Y., 2018. "Risk and Efficiency Analysis of Dual Mixed Refrigerant Liquefaction Process Configurations for Floating Liquefied Natural Gas at Conceptual Design Stage.” Process Safety Progress, 38(1), 87-98. https://doi.org/10.1002/prs.11994 